\title{
MUSCLE RECEPTOR ORGANS IN THE PAGURIDAE
}

\author{
By J. S. Alexandrowicz \\ From the Plymouth Laboratory \\ (Plate I and Text-figs. I-2)

\section{Material AND Methods}

The occurrence of muscle receptor organs in stomatopods and decapods being established, it seemed worth while to extend investigation to the hermit crabs (Paguridae), the more so as the thinness of the dorsal wall of the abdomen in these animals offered favourable conditions for examination of the nerve elements in this region. The first observations made in 1939 at Naples on Pagurus striatus revealed in its abdominal segments the presence of nerve cells connected with muscles which undoubtedly represented similar receptor organs to those found in other crustaceans. When, however, I tried later to investigate these organs in Eupagurus bernhardus, the commonest hermit-crab in Plymouth waters, I was unsuccessful in obtaining suitable preparations. Eupagurus prideauxi gave better results, but these, too, were inferior to those given previously by Pagurus. With a fresh opportunity to work at Naples in autumn 1950, I resumed the investigations with $P$. striatus and also with $P$. calidus which proved to be very suitable for this purpose. The present account is based chiefly on these two species of the subfamily Pagurinae. Observations on Eupagurus prideauxi have shown that their muscle receptor organs, apart from some unimportant differences in their topography, are made on the same pattern and therefore the description given holds good for the two subfamilies of the Paguridae.

The nervous elements were stained by the same methylene-blue technique described previously (Alexandrowicz, $195 \mathrm{I}^{1}$ ). Either the dye was injected into the body of the animal or the tissue was submerged in a solution of the dye, or both. The abdomen was cut along the middle line of the ventral wall and pinned to a paraffin plate with the inside turned upwards. The small 6th segment was not dissected and left out of consideration. All the organs situated in the abdominal sac were removed, and the surface of the muscles cleaned from the attached strands of tissue. The preparations were then put into the methylene-blue solution. The methods of fixation and further procedure were the same as set down in the paper quoted.

${ }^{1}$ Muscle receptor organs in the abdomen of Homarus vulgaris and Palinurus vulgaris, Quart. Fourn. Micr. Sci., Vol. 92, p. 163. 


\section{OBSERVATIONS}

\section{Topography of the Dorsal Muscles in the Abdomen}

Text-fig. I A shows the dorsal wall and parts of the lateral walls of the abdomen of Pagurus seen from the inside. Of the Ist segment only the dorsal muscles are seen: they are composed of three portions each having a slightly different obliquity of its fibres. Of the following four segments (2nd to 5 th) the dorsal body-wall and parts of the lateral walls are represented.

The dorsal portion has a segmental arrangement of the muscles and is. distinctly delimited from both sides by a gap in the muscle layer. The dorsal (extensor) muscles consist of parallel longitudinal fibres, the length of which corresponds with the length of the respective segments. The fibres of the successive segments meet end to end and become attached along the lines marking the limits between the segments.

Near the anterior edges of the segments there are small transverse muscles situated asymmetrically on the left side. Their fibres converge towards the basis of each pleopod.

In the lateral walls the muscles are set in three layers. Those of the outer layer are oblique, those in the middle transverse, while the fibres of the inner layer have a more complicated disposition. They are chiefly longitudinal, forming stronger bundles along the gap separating them from the dorsal muscles; more laterally, both longitudinal and oblique fibres are present, anastomosing with each other. Since the oblique fibres of this inner layer intercross the direction of those of the outer layer, there are places where fibres running in four different directions can be seen.

The median longitudinal bundles of the inner layer, being interrupted on the left side by the transverse muscles of the pleopods, show a segmental arrangement: all other muscles of the lateral wall do not exhibit any segmentation.

\section{Muscle Receptor Organs}

As in Homarus and Palinurus, the two species of Macrura investigated (loc. cit.), there are in the Paguridae two pairs of muscle receptor organs in . each of the Ist to 5 th abdominal segments. They are each composed of a very thin but long muscle and a nerve cell which connects with the muscle by means of dendritic processes and sends its axon towards the central nervous system (Text-fig. I B; Pl. I, fig. I). The two muscle receptors situated on the same side, which must be regarded as individual units, each have particular features of their own. Their cells are of two different types, one having very long and the other very short distal processes. In the further description the cell of the first type will be referred to as cell $\mathrm{I}$ and that of the second type as cell 2, and the muscles connected with these cells as RMI and RM 2 respectively. For designation of the muscle receptor organ as a whole the abbreviation MRO will be used. 

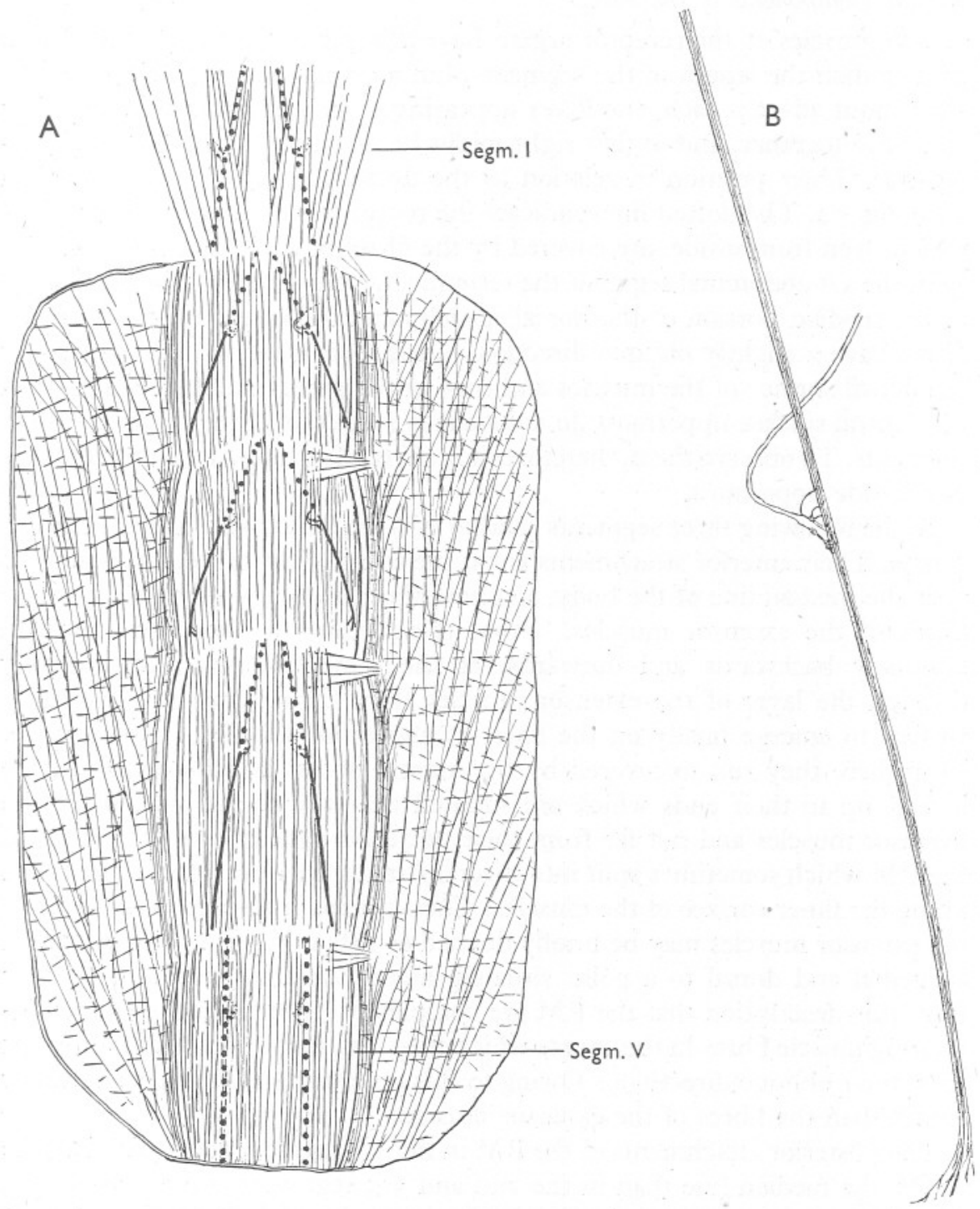

Text-fig. I. A, view of the dorsal wall and parts of the lateral walls of the Ist to 5 th abdominal segments in Pagurus showing the position of the muscle receptor organs in relation to the dorsal muscles. The two MRO on each side are represented by a single line; the dotted line shows the MRO or their parts which, seen from inside, are covered by the fibres of the dorsal muscles. B, two muscle receptor organs of the 2nd segment showing their relative length and thickness, drawn to scale. The axons of the receptor cells viewed from inside appear as passing under the muscles; actually they cross these muscles on their dorsal side. 


\section{Muscle Components of the MRO}

The muscles of the receptor organs have a length equal to or even slightly greater than the length of the segments, but are very thin having a diameter only about 30-40 $\mu$ each, the RMI appearing to be somewhat thicker. They run close together, and at first sight might be taken for a single fibre (Textfig. I B). Their position in relation to the dorsal muscles is represented in Text-fig. I A. The dotted lines indicate the receptor muscles or their portions which, seen from inside, are covered by the fibres of the dorsal muscles.

In the Ist abdominal segment the receptor muscles run near the outer edge of the median portion of the dorsal muscle, and following the course of its fibres have a slightly oblique direction. In this segment the RM lie nearer the dorsal surface of the muscles and thus in the preparations stretched with the ventral surface uppermost do not stain as readily as in the following three segments. To observe them, therefore, it is advisable to attach the preparations dorsal side uppermost.

In the following three segments (2nd to 4 th) the RM have a nearly identical course. Their anterior attachments are at the edges of the respective segments near the median line of the body, and here the RM lie dorsally, i.e. upon the fibres of the extensor muscles. From these points of insertion they run obliquely backwards and outwards, at the same time passing gradually through the layer of the extensor muscles from their dorsal to the ventral surface to emerge finally on the latter at about the middle of their course. From here they run uncovered by the muscle fibres (as observed from the inside) up to their ends which are situated near the lateral margins of the extensor muscles and not far from their posterior attachments. The ends of the RM which sometimes split into several strands are inserted into the fascia lining the inner surface of the muscles. Their course in respect to the layer of the extensor muscles may be briefly defined as extending from a point which is medial and dorsal to a point situated laterally and ventrally. It is clear from this description that the RM are completely independent of the neighbouring muscle fibres in the course which they run, as is at first sight apparent from their oblique directions. Owing to this obliquity the RM have a greater length than the fibres of the extensor muscles.

The posterior attachments of the RM in the 4 th segment are situated a little nearer the median line than in the 2nd and 3 rd segments and as, moreover, the 4th segment is much longer than the others, its RM have a less oblique course.

In the 5th segment the RM anteriorly have superficial attachments similar to those in the foregoing. Running backwards they pass deeper into the layer of the dorsal muscles but do not emerge on their ventral surface, ending between the dorsal muscles at the edge of the segment. In all their course they remain nearly parallel to the median line. Owing to their deeper setting they usually stain less distinctly or even remain invisible. 
The arrangement of the RM in Pagurus calidus is the same as in P. striatus. In Eupagurus prideauxi the RM have a less oblique direction and run a little farther from the ventral surface. Their still deeper setting in the muscle layer is presumably responsible for the failure in getting satisfactory staining in $E$. bernhardus. In the Ist abdominal segment of that species, where the dye can have access from the dorsal side to the superficially situated MRO they stain quite well.

It is easy to recognize the two RM as individual muscle units owing to their remarkable property of staining differentially in methylene blue. As a rule one of them, and this is nearly always RM I, remains almost colourless, while the other stains blue or even dark blue (Pl. I, figs. I, 5). Rarely the reverse reaction is observed and also rarely both RM appear stained in the same or nearly the same hue. Thanks to this difference in colour it may be stated that RMI is situated laterally and somewhat dorsally to RM2. The differences in the appearance of the two muscles might not, of course, be noticeable when the action of the methylene blue was not long enough or was impeded-as for instance in the anterior portion of the RM situated within the muscle layer-and not easily reached by the dye. For that reason it has been difficult to determine whether both muscles have their anterior insertions at exactly the same point or, as was found in Homarus, at different points. It may, however, be assumed that if there is separation between these points of attachment it cannot be great.

The receptor muscles have a similar structure as in the Macrura, i.e. are composed of bundles of myofibrils and of connective tissue fibres running longitudinally between them. The connective fibres are more abundant in RM I than in RM $2 .^{1}$

\section{Nerve Cells}

The nerve cells are situated at about the middle of the length of the receptor muscles, rather a little anterior to the mid-point, and consequently they lie near the place at which the MRO appear on the ventral surface of the muscle layer; hence in the preparations with this surface uppermost the nerve cells can be well exposed for observation. It happens however, not uncommonly, that they are covered by some muscle fibres, to remove which an attempt should be made cautiously.

In the first segment the nerve cells are situated on the lateral side of their muscles, whereas in the 2 nd to 5 th segments they lie on the median side. Cell 2 lies behind, and usually close to, cell I, but the two cells may sometimes

${ }^{1}$ As in previous papers, I prefer to avoid the term 'muscle fibres' when describing the components of the MRO. Being thread-like, they are fibres in the general meaning of this word, but they are not 'muscle fibres' in a strict histological sense, i.e. elements of striated muscular tissue consisting of myofibrils embedded in sarcoplasm with many nuclei and enclosed in a sarcolemma-tube. 
be well separated. They differ greatly in their appearance, in the distribution of their processes, and even in their staining properties.

Cell I is multipolar, and with its processes arising from various points of the body can have a manifold shape (Pl. I, figs. I-5). The processes, one or two of which may arise from the axon, pass on to the muscle RMI and run in opposite directions giving off numerous ramifications (Text-fig. 2A). They look quite like the fibres of nerves coming to the receptors from the central nervous system (Pl. I, figs. 3, 4). When associated with the latter in a common bundle the cell processes can be identified only if it is possible to trace them up to the cell and thus detect their origin. This makes it difficult to determine their whole course, but they are seen running far in both directions. As in no instance can the limit of their expansion be noticed, it seems not improbable that they might extend along the whole length of the muscle. The terminations of the longer branches from among those of other fibres are indistinguishable. Those of the branches ending nearer the cell and whose origin is unquestionable are seen to give fine filaments spreading in the RMI. Since in all the MRO examined in the Macrura the ramifications of the cell processes end not on the muscle itself but on the connective tissue, it is probable that in the Paguridae too the terminations of the cell processes are situated on the connective tissue fibres, which, as mentioned before, are abundant in RMI. Unfortunately, it is practically impossible to discern the relations of particular nerve filaments, as in the thin receptor muscle all the elements, viz. myofibril bundles, connective tissue fibres and nerve fibres of various origins, run closely intermingled.

Cell 2 is as a rule bipolar with a thick distal process which gives off very short branches. These ramify abundantly and penetrate into RM forming a sort of tuft which occupies the whole thickness of the muscle, but only a small portion of its length, about three times as large as the diameter of the muscle (Text-fig. 2 A, Pl. I, figs. I, 3). The tuft of nerve branches is so dense that when it is well stained the muscle appears as if it were completely interrupted at this place by the nerve fibres. There is there, of course, connective tissue too.

On the periphery of the cell 2 small blue staining granules can often be observed. Possibly they are disintegrated fine nerve fibres surrounding the cell body.

The axons of the cells join branches of motor nerves running near by. In the first segment the axons are directed laterally. In the 2nd to 5th segments they run at first medially then curve dorsally and laterally, thus crossing the receptor muscles (Text-fig. I B). The nerve branch into which they pass near their origin is one of the motor branches supplying the median portion of the extensor muscles.

Both nerve cells are protected by connective tissue arranged in concentric layers. When the cells shrink a little it may be seen that there is a sort of 

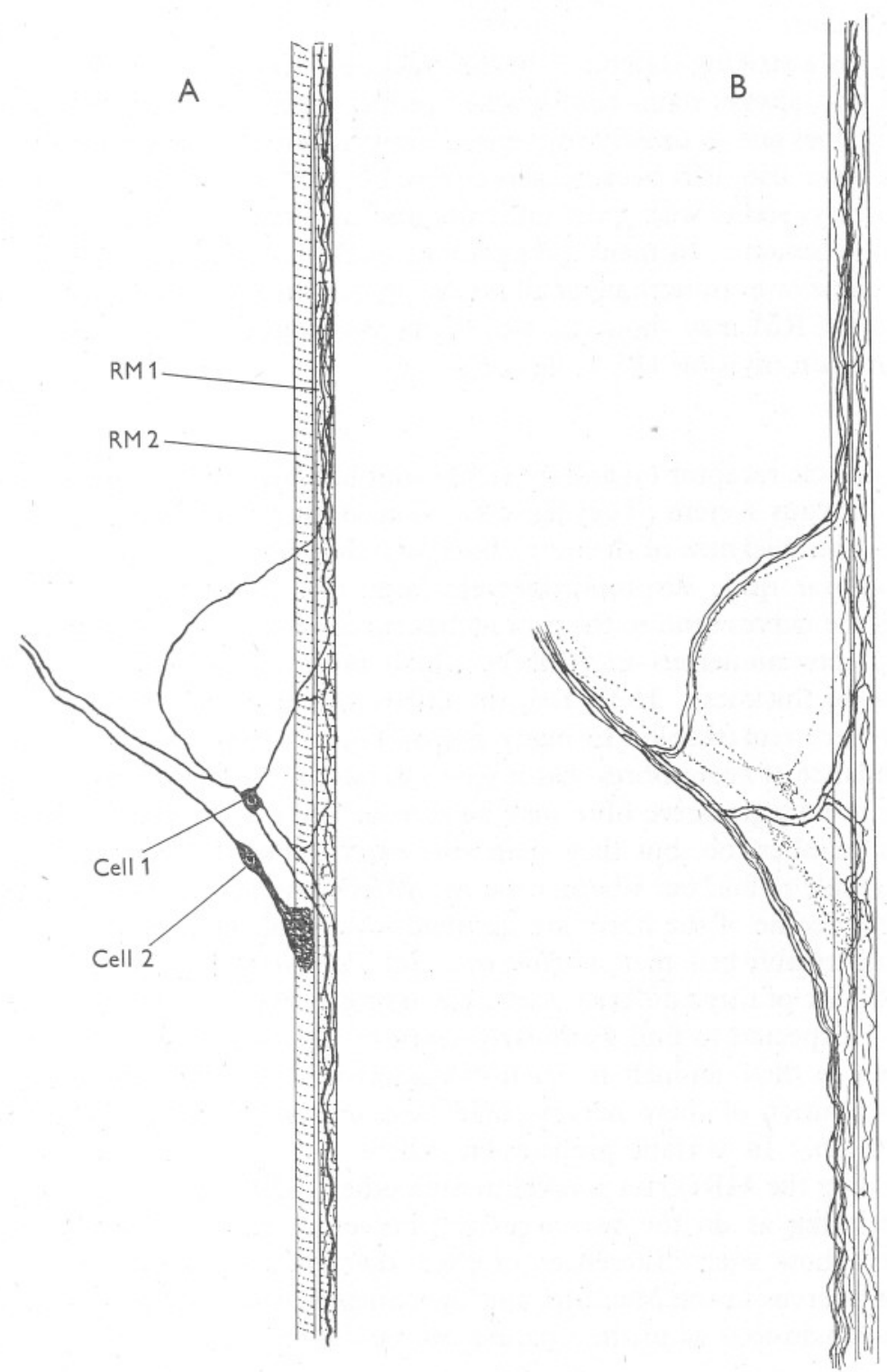

Text-fig. 2. Semi-diagrammatic view of muscle receptor organs showing in A the nerve cells with their processes and in B the nerve-fibres of central origin supplying the MRO. In both drawings the parts lying anteriorly in the animal body are shown at the top of the figures. 
capsule around them but it does not leave such a wide space around the cells as in Homarus.

There is a striking difference in the reaction of the two cells to methylene blue. Cell I always stains readily when properly exposed to the action of this dye. If it does not, as usually happens in the 5 th segment and not uncommonly in the others also, it is because it is covered by the muscle fibres. Cell 2, on the contrary, stains with great difficulty and no similar reason can be found for this behaviour. In many preparations only faint outlines of this cell are recognizable or even nothing at all reveals its presence-only a slight enlargement of the RM may show the area of the distribution of the cell dendrites which remain invisible (Pl. I, fig. 2c).

\section{Nerves}

The muscle receptor organs are richly supplied by nerves coming from the central nervous system (Text-fig. 2 B). Considering the small calibre of the muscles, the thickness of the nerve bundle and its fibres running towards the MRO appear quite disproportionately large (P1. I, fig. 5). Reaching the muscles the nerves send to them branches running in opposite directions and dividing into numerous finer fibres which penetrate the muscles through their whole thickness. Here, too, the differences in the staining of the two $\mathrm{RM}$ are very remarkable. In many preparations in which RM I shows such an abundance of nerve fibres that it seems to have more nerves than any other tissue, not a single nerve fibre may be seen in RM2. In fact, they are there in great number too, but they stain very rarely. For this reason it has not been possible to find out whether the two MRO have an identical innervation or whether some of the fibres are destined for one of them only.

Having established that in Homarus and Palinurus the nerves supplying the MRO are of three different sorts, viz. motor nerves and the two accessory nerves, I expected to find a similar pattern of innervation in the Paguridae. However, in these animals no such characteristic features in the appearance and distribution of these nerves could be found which would permit their classification. In certain preparations there can be seen that the fibres approaching the MRO run parallel to each other and divide at the same spot, thus behaving as do the two accessory nerves in Homarus. They do not, however, show such differences of their diameters as the thick and thin accessory nerves in the Macrura, and their further course being uncertain no definite conclusions as to their nature can be drawn.

\section{Comparison of the Paguridae with the Macrura}

As has been pointed out before, the MRO in the abdomen of the Paguridae are made up on the same lines as in the Macrura but there are some differences. For instance, the muscles of the same pair in the Macrura have as a rule their attachments at a certain distance from one another, can have 
a more or less different course, and can differ greatly in their length. In the Paguridae they run close together and appear to be of equal or nearly equal lengths. The dissimilarities in their histological structure are much less distinct than in the Macrura, and only the staining properties indicate that they are not of the same kind. On the other hand, in the nerve cells of the Paguridae the characteristic features distinguishing the two types of receptors, viz. the length of the distal cell processes, are accentuated to the highest degree. In fact, the processes of cell I extending along the muscle attain unusual dimensions. In the Macrura these processes expand on a limited area which is merely a little larger than that of cell 2 .

It should be noted that in certain thoracic muscles in Homarus and Palinurus there are nerve cells which resemble somewhat cell I in Pagurus in that they give off long processes ending between the muscle fibres. However, these cells (termed 'cells N') do not belong to the same category of receptors as those situated in the dorsal muscles, for they have not their own receptor muscle and otherwise differ in appearance from the former. ${ }^{1}$

Comparing the nerve supply of MRO in both groups it may be briefly stated that in the Paguridae there are even more than enough fibres for carrying to the MRO the same elements of various sorts as found in the Macrura, but that the disposition of these elements has not been discerned.

In the above account, the MRO in the thoracic segments, as described in the Macrura, has not been taken into consideration although they are certainly present in the Paguridae too. I have seen them in all the four species investigated. One of these $\mathrm{MRO}$, situated superficially on the dorsal side of the thoracico-abdominal muscle, is quite easily noticeable. Since in the thorax of the Macrura four MRO have been found on each side it seemed very probable that the Paguridae should have the same number. However, owing to technical difficulties, I have thus far been unable to find their position or to convince myself that some of these elements are missing in these animals.

\section{Function}

When describing the MRO in the Macrura I ventured some suggestions about their function, assuming that they are connected with the action of the system of giant fibres and may perhaps be inhibitory to the latter during the flipping movements of the abdomen. As the MRO in the Paguridae look so like those of the Macrura, it is hardly probable that they would have a different function, but since the abdomen of hermit-crabs does not perform flipping movements the question arises, if the above hypothesis should hold good, what indeed may be the reason for existence of the MRO in these animals. The problem is even more complicated, since an explanation has to be found why the two MRO are so different from each other.

\footnotetext{
1 The paper on the receptor elements in the thoracic muscles of Homarus and Palinurus is being published in Quart. Fourn. Micr. Sci.
} 
I wish to express my thanks to Prof. Dr R. Dohrn, Director of the Zoological Station, Naples, for his kindness and hospitality and to the British Association for the Advancement of Science for the use of its Table.

I am indebted to Mr G. M. Spooner for his kind help in preparing the manuscript.

\section{SUMMARY}

In the dorsal wall of the abdomen in the Paguridae muscle receptor organs have been found similar to those in the Macrura. In each of the first to fifth abdominal segments there are two receptor units on each side. A receptor unit consists of a long thread-like muscle, and a nerve cell connected with this muscle and sending its axon towards the central nervous system. The muscles of each pair run close together in the layer of the dorsal (extensor) muscles, but are independent from the latter following a more or less different course.

The nerve cells in each pair of muscle receptor organs are of two types. One of them has several very long distal processes expanding over one of the muscles. The other cell has one stout distal process giving off numerous but very short branches forming with their subdivisions a dense tuft of fibres terminating in the second muscle. The axons of the cells associate with one of the branches of motor nerves supplying the dorsal muscles and pass along these branches into the main nerve trunks of the respective segments.

Each receptor organ is supplied by several nerve fibres coming from the central nervous system.

\section{EXPLANATION OF PLATE I}

All photomicrographs were made from preparations stained with methylene blue, fixed in ammonium molybdate and mounted in xylol-dammar.

Figs. 2-5 have been made with the same magnification. The differences in dimensions of cells represented depend on the various sizes of specimens.

The uneven outlines and irregular courses of the receptor muscles seen at some places are due to deformations caused when isolating the muscle receptor organs from the abdominal wall.

The parts lying anteriorly in the animal body are shown at the top of the figures.

Fig. I. Pagurus calidus. Middle portion of the muscle receptor organs of the 2nd abdominal segment showing their oblique course in relation to the dorsal muscles. The latter have been partly removed. Note the position of the two nerve cells, the difference of their shapes, the unequal staining of the two receptor muscles and the medial position of the darker stained RM 2.

Fig. 2. P. striatus. Cell I with several processes passing on to the muscle RMI. ax, its axon joining the nerve; $b$, process arising from the axon and associating with a nerve branch to reach RMI at a point distant from the cell; $c$, area of distribution of the processes of cell 2 , the latter being invisible.

Fig. 3. P. calidus. Receptor organs with the cells showing the different expansions of their processes. The unusual situation of the cells is produced artificially at fixation. ax, axons of both cells.

Fig. 4. P. calidus. Cell I with processes associating with the nerve-fibres of central origin.

Fig. 5. P. calidus. Cell $\mathrm{I}$ and the bundle of nerve fibres of central origin supplying the MRO. The branches of the nerves, most of them disintegrated in granules, are seen spread in RM I, but not in the RM2 (darker stained). 


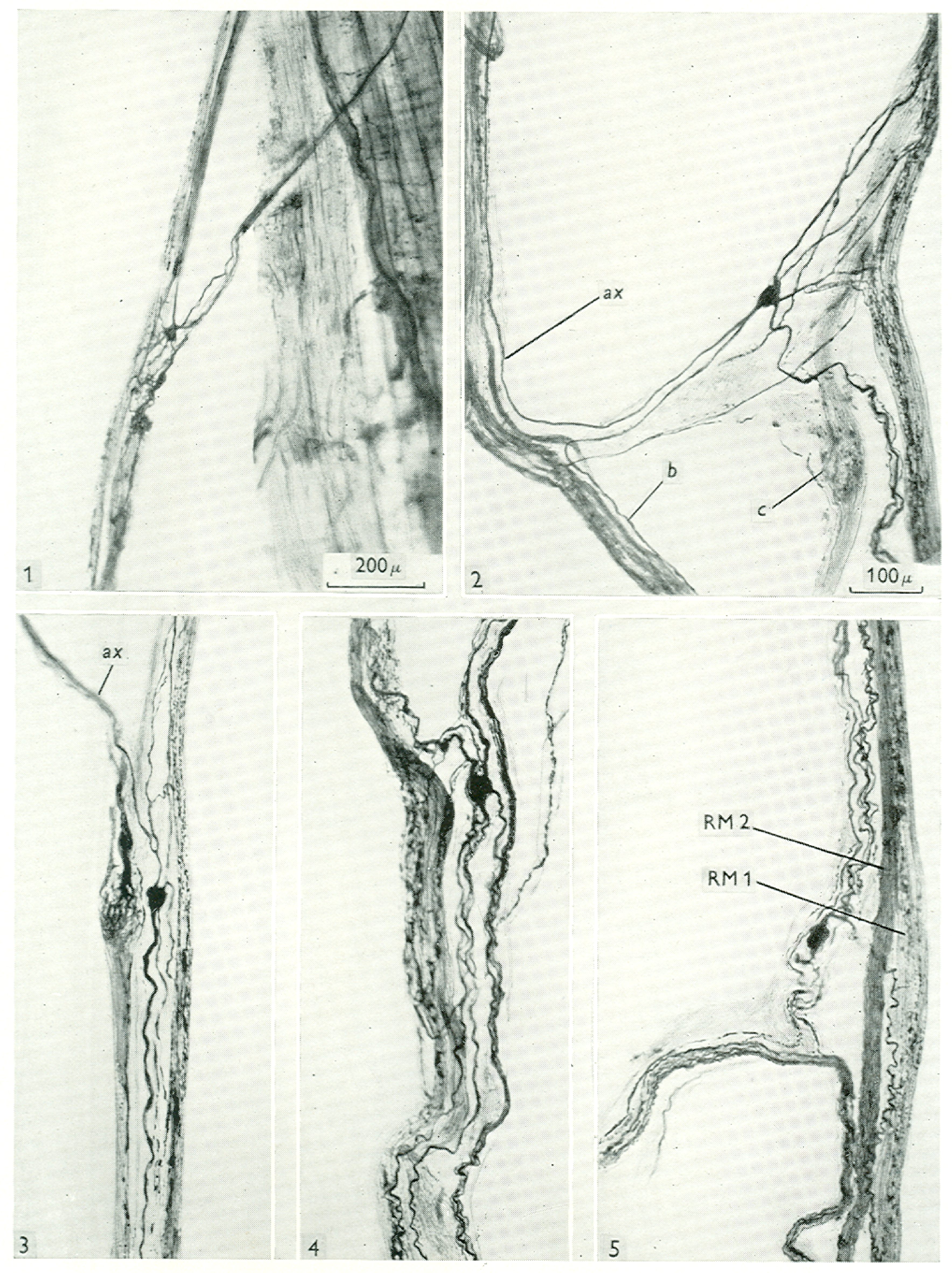

